\title{
Statistics and Bioscience: Association in Research
}

\author{
Dhritikesh Chakrabarty* \\ Department of Statistics, Handique Girls' College, India \\ *Corresponding author: Dhritikesh Chakrabarty, Department of Statistics, Handique Girls' College, Guwahati -781001, Assam, India
}

Submission: September 07, 2018; Published: December 11, 2018

\begin{abstract}
Statistics has been found to be a major player in playing the role of understanding various phenomena in almost every branch of science. This paper describes (i) the meaning, definition \& role of statistics and of bioscience, (ii) the idea of research in general \& of bioscience research specifically and (iii) the association of statistics with research in general and with bioscience research specifically.
\end{abstract}

Keywords: Statistics; Bioscience; Research; Basic role; Association

\section{Introduction}

Statistics is an old discipline, as old as the human activity. Its utility has been increasing as the ages goes by. In the olden days it was used in the administrative departments of the states and the scope was limited. Earlier, it was used by governments to keep record of birth and death population etc. for administrative purpose [1]. John Graunt was the first man to make a systematic study of birth and death statistics and calculation of expectation of life at different age in the $17^{\text {th }}$ century which led to the idea of Life Insurance. However, the history of the beginning of the development of the theory of statistics was lost in the dust of antiquity [2-6].

Statistics has been found to be a major player in playing the role of understanding various phenomena in almost every branch of science. At the current stage of human civilization, statistics has become an unavoidable and essential analytical tool for scientific research [7].

Research has been found to be (i) an essential \& unavoidable component of academic activity, (ii) the best intellectual helper in solving any type of the problem and (iii) the vital player in playing the role of searching for new information/knowledge [7]. This, together with the fact mentioned above, establishes the importance of research in general and specially in bioscience. Moreover, Statistics is also essential and unavoidable tool for scientific investigation and research [7]. Accordingly, there is necessity of study on the association of statistics in bioscience research. In pursuance of this necessity, attempt has here been made on searching for the association of statistics with research in general and specifically with bioscience research. In this paper, discussion has been made on the meaning, definition \& role of statistics and of bioscience, the idea of research in general \& of bioscience research specifically and (iii) the association of statistics with research in general and with bioscience research specifically.

\section{Statistics - Its Identity}

\section{Meaning of statistics}

The word "Statistics" seems to have been derived from the Latin word "status" or Italian word "statista" or the German word "Statistik" each of which means a political state [8-11]. Fields like agriculture, economy, sociology, business management etc. are now using Statistical Methods for different purpose. The first part of the word "statistic" comes from the German word "staat" for state. The word was used as a term to describe the practice of the state collecting information on births and deaths more than 300 years ago [9,12-14]. At the current stage, two words namely "Statistics" and "Statistic" are used in the theory of statistics. The word "Statistics" is used to mean data / information on events, phenomena, experiments etc. On the other hand, the word "Statistic" is used to mean the method of operation on data. The word "Statistic" is used to mean the function of data applied in determination problem (called estimation in the literature of statistics) and in testing problem (called hypothesis testing in the literature of statistics).

\section{Definition of statistics}

The existing definitions of statistics can be broadly classified into two types namely (A) definition as statistical data and (B) definition as statistical method.

Statistics as statistical data: Statistics have been defined, as statistical data, as follows

$[4,6]$. 
a. According to Webster, statistics are the classified facts representing the conditions of the people in a state, especially those facts which can be stated in numbers or any tabular or classified arrangement.

b. According to Yule and Kendall, statistics means quantitative data affected to a marked extent by multiplicity of causes.

c. Professor Bowley defined statistics as the numerical statements of facts in any department of enquiry placed in relation to each other

d. Prof. Horace Secrist defined statistics as aggregates of facts affected to a marked extent by multiplicity of causes, numerically expressed, enumerated or estimated according to reasonable standards of accuracy, collected in a systematic manner for a predetermined purpose and placed in relation to each other

\section{Statistics as statistical method}

Statistics have been defined, as statistical method, as follows $[6,15]$.

a. Professor Bowley defined statistics as the Science of Counting, Averages \& Measurement of Social Organism.

b. According to Boddington, statistics is the science of estimates and probabilities.

c. According to King, the science of statistics is the method of judging collective, natural or social phenomena from

d. According to Lovitt, the science of statistics is the method of judging collective, natural or social phenomena from the analysis or enumeration or collection of estimates.

e. Croxton and Cowden defined statistics as the science which deals with the collection, analysis and interpretation of numerical data. This definition is the universally accepted definition of statistics at the current stage of the development of statistical science.

\section{Jobs in statistics}

The definitions of statistics, as mentioned above, imply that the jobs to be done in statistical science can be broadly treated as the following three-stage jobs:

a. Collection of Data (comprising Scrutiny, Classification and representation of Data)

b. Analysis of Data.

c. Interpretation of Results (comprising of Interpretation of Results/Findings \& Drawing of Conclusion/Inference)

\section{Bioscience - Its Identity}

The idea and concept of bioscience [16-18] can be explained as follows.

\section{Meaning \& definition of bioscience}

Any of the branches of natural science dealing with the structure and behavior of living organisms is bioscience. The following points clearly express the meaning and definition of bioscience.

a. Biosciences are at the core of many innovations that lead to products that cure diseases, ensure we have safe and abundant food and water, and contribute to creating new fuels.

b. Biotechnology is the fusion of bioscience with technology to create and shape industries and products.

c. Bioscience is the broad term for any type of science dealing with life, like botany, biology, medical, or health science. Genetics, immunology, and biochemistry would also fit in this category.

d. Bioscience is the study of biology wherein all the applicable sciences (physics, chemistry, etc.) are applied.

e. Bioscience is any of the branches of natural science dealing with living things, such as their structure, behavior, organization, life processes, as well as their interactions with each other and with the natural environment.

f. Bioscience is any science that deals with the biological aspects of living organisms.

g. Bioscience is any science that deals with the functions or problems of living organisms.

h. Bioscience is an area of scientific study that relates to living things, for example biology or biochemistry.

Bioscience, life science are synonyms of bioscience. Each of the following is a kind of bioscience:

a. Natural science - the sciences involved in the study of the physical world and its phenomena.

b. Biological science ( $\&$ also biology) - the science that studies living organisms.

c. Euthenics - the study of methods of improving human well-being and efficient functioning by improving environmental conditions.

d. Cacogenics ( \& also dysgenics) - the study of the operation of factors causing degeneration in the type of offspring produced.

e. Eugenics - the study of methods of improving genetic qualities by selective breeding (especially as applied to human mating).

f. Dietetics - the scientific study of food preparation and intake.

g. Dermatoglyphics - the study of the whorls and loops and arches in the fingertips and on the palms of the hand and the soles of the feet.

h. Craniology - the scientific study of the skulls of various human races.

i. Biometrics (also Biometry \& Biostatistics) - the science that studies biological phenomena and observations by means of statistical analysis. 
j. Biomedical science - the application of the principles of the natural sciences to medicine.

k. Medical science - the science of dealing with the maintenance of health and the prevention and treatment of disease.

\section{Biology}

Biology [19], one prime field of bioscience, carries the following definitions and fields of study.

\subsubsection{Definitions}

a. Biology deals with the study of the many varieties of living organisms.

b. Biology is a natural science concerned with the study of life and living organisms, including their structure, function, growth, evolution, distribution, and taxonomy.

\section{Fields of study in biology}

Following are some, but not exhaustive, fields of biology:

1. Aerobiology - the study of airborne organic particles.

2. Agriculture - the study of producing crops from the land, with an emphasis on practical applications.

3. Anatomy - the study of form and function, in plants, animals, and other organisms, or specifically in humans.

4. Arachnology - the study of arachnids

5. Astrobiology - the study of evolution, distribution, and future of life in the universe-also known as exobiology, exopaleontology, and bioastronomy

6. Biochemistry - the study of the chemical reactions required for life to exist and function, usually a focus on the cellular level.

7. Bioengineering - the study of biology through the means of engineering with an emphasis on applied knowledge and especially related to biotechnology.

8. Biogeography - the study of the distribution of species spatially and temporally.

9. Bioinformatics - the use of information technology for the study, collection, and storage of genomic and other biological data.

10. Biomathematics (or Mathematical biology) - the quantitative or mathematical study of biological processes, with an emphasis on modeling.

11. Biomechanics - often considered a branch of medicine, the study of the mechanics of living beings, with an emphasis on applied use through prosthetics or orthotics.

12. Biomedical research - the study of the human body in health and disease.

13. Biomusicology - study of music from a biological point of view.

14. Biophysics - the study of biological processes through physics, by applying the theories and methods traditionally used in the physical sciences.

15. Biotechnology - a new and sometimes controversial branch of biology that studies the manipulation of living matter, including genetic modification and synthetic biology.

16. Building biology - the study of the indoor living environment.

17. Botany - the study of plants.

18. Cell biology - the study of the cell as a complete unit, and the molecular and chemical interactions that occur within a living cell.

19. Conservation biology - the study of the preservation, protection, or restoration of the natural environment, natural ecosystems, vegetation, and wildlife.

20. Cryobiology - the study of the effects of lower than normally preferred temperatures on living beings.

21. Developmental biology - the study of the processes through which an organism forms, from zygote to full structure.

22. Ecology - the study of the interactions of living organisms with one another and with the non-living elements of their environment.

23. Embryology - the study of the development of embryo (from fecundation to birth)

24. Entomology - the study of insects.

25. Environmental biology - the study of the natural world, as a whole or in a particular area, especially as affected by human activity.

26. Epidemiology - a major component of public health research, studying factors affecting the health of populations.

27. Epigenetics - the study of heritable changes in gene expression or cellular phenotype caused by mechanisms other than changes in the underlying DNA sequence.

28. Ethology - the study of animal behavior.

29. Evolutionary biology - the study of the origin and descent of species over time.

30. Genetics - the study of genes and heredity.

31. Hematology (also known as Haematology) - the study of blood and blood - forming organs.

32. Herpetology - the study of reptiles and amphibians.

33. Histology - the study of cells and tissues, a microscopic branch of anatomy.

34. Ichthyology - the study of fish.

35. Integrative biology - the study of whole organisms.

36. Limnology - the study of inland waters. 
37. Mammalogy - the study of mammals.

38. Marine biology (or Biological oceanography) - the study of ocean ecosystems, plants, animals, and other living beings.

39. Microbiology - the study of microscopic organisms (microorganisms) and their interactions with other living things.

40. Molecular biology - the study of biology and biological functions at the molecular level, some cross over with biochemistry.

41. Mycology - the study of fungi.

42. Neurobiology - the study of the nervous system, including anatomy, physiology and pathology.

43. Oncology - the study of cancer processes, including virus or mutation oncogenesis, angiogenesis and tissues remolding's.

44. Ornithology - the study of birds.

45. Population biology - the study of groups of conspecific organisms, including.

46. Population ecology - the study of how population dynamics and extinction.

47. Population genetics - the study of changes in gene frequencies in populations of organisms.

48. Population genetics - the study of changes in gene frequencies in populations of organisms.

49. Paleontology - the study of fossils and sometimes geographic evidence of prehistoric life.

50. Pathobiology or pathology - the study of diseases, and the causes, processes, nature, and development of disease.

51. Parasitology - the study of parasites and parasitism.

52. Pharmacology - the study and practical application of preparation, use, and effects of drugs and synthetic medicines.

53. Physiology - the study of the functioning of living organisms and the organs and parts of living organisms.

54. Phytopathology - the study of plant diseases (also called Plant Pathology).

55. Psychobiology - the study of the biological bases of psychology.

56. Sociobiology - the study of the biological bases of sociology.

57. Structural biology - a branch of molecular biology, biochemistry, and biophysics concerned with the molecular structure of biological macromolecules.

58. Synthetic Biology- research integrating biology and engineering; construction of biological functions not found in nature.

59. Virology - the study of viruses and some other virus-like agents.
60. Zoology - the study of animals, including classification, physiology, development, and behavior (branches include: Entomology, Ethnology, Herpetology, Ichthyology, Mammalogy, and Ornithology).

\section{Research in General \& in Bioscience}

\section{Meaning of research}

Research is a detailed study of a subject, especially in order to discover (new) information or reach a (new) understanding. Following seven points can express the meaning and definition of research [7,20-22]

a. Research basically means the studies involving search for new information / new knowledge.

b. Searching for the facts that are in the dark, searching for the replies to the various queries, searching for solutions to various problems etc. are research activities.

c. Establishing Facts, Analyzing Information and Reaching New Conclusions are the basic three goals of research while Searching For, Reviewing \& Evaluating Information are the three main acts of doing research.

d. A scientific investigation of phenomena is that which includes Collection, Presentation, Analysis \& Interpretation of Facts that link man's speculation with reality.

e. Research can be defined to be a process of investigation, an examination of a subject from different points of view.

f. Research can be defined as the creation of new knowledge and/or the use of existing knowledge in a new and creative way so as to generate new concepts, methodologies and understandings which includes synthesis and analysis of previous research to the extent that it leads to new and creative outcomes.

g. Research can be interpreted as a hunt for the truth.

\section{Types of research}

Researches can be of many types: Following are some types of research are as follows:

a. Theoretical researches: conceptual type, theory development type \& methodological type of researches.

b. Applied type of researches: art of application type \& application in real situation (reality) type of researches.

c. Experimental type of researches: theory-development type \& applied type of researches.

d. Non-experimental type of researches: theorydevelopment type \& applied type of researches.

e. Original type of researches.

f. Extension type of researches.

g. Modification type of researches.

h. Application of existing theory type of researches. 
i. Observational Research

j. Case Study Research.

k. Survey Research.

l. Delphi Research.

m. Basic Research.

n. Developmental Research.

o. Library Research.

p. Field Research.

q. Laboratory Research.

r. Qualitative Research.

s. Quantitative Research.

t. Mixed Research.

$[3,7,20-24]$.

\section{Steps in research process}

Scientific research involves a systematic process that focuses on being objective and gathering a multitude of information for analysis so that the researcher can come to a conclusion. The scientific research process is a multiple-step process where the steps are interlinked with the other steps in the process. The usual eight steps of the research process [20-22] are as follows:

i. Step 1: Identify the Problem: The first step in the process is to identify a problem or develop a research question.

ii. Step 2: Review the Literature: This step provides foundational knowledge about the problem area.

iii. Step 3: Clarify the Problem: In this step, the researcher clarifies the problem and narrows the scope of the study. This can only be done after the literature has been reviewed.

iv. Step 4: Clearly Define Terms and Concepts: Terms and concepts used in research need to be specifically defined in this step.

v. Step 5: Define the Population: The population, the group of individuals to be involved in research, the study is identified and/ or defined clearly in this step.

vi. Step 6: Develop the Instrumentation Plan: The instrumentation plan i.e. the plan for the study, which serves as the road map for the entire study, needs to be developed in this step.

vii. Step 7: Collect Data: Once the instrumentation plan is completed, the actual study begins with the collection of data. Data can be collected in the form of words on a survey, with a questionnaire, through observations, or from the literature. Once the data are collected on the variables, the researcher is ready to move to the final step of the process, which is the data analysis.

viii. Step 8: Analyze the Data: All the time, effort, and resources dedicated to steps 1 through 7 of the research processes culminate in this final step. The researcher finally has data to analyze so that the research question can be answered. In the instrumentation plan, the researcher specified how the data will be analyzed. The researcher now analyzes the data according to the plan. The results of this analysis are then reviewed and summarized in a manner directly related to the research questions.

\section{Steps of works in bioscience research}

From the eight steps of research process [20-22] and from the jobs to be done in research [7], the works to be done in bioscience research, in general, can be classified in the following steps arranged in chronological sequence:

1. Association to Problem: In the first step, researcher/ investigator requires to be associated with the problem existing in the field of interest.

2. Detection of Problem (for imposed research) / Fixing of Problem (for own research, thrust, adventure etc.): In the next step, researcher/investigator requires to detect the problem(s) existing in the field of interest which need(s) research/investigation.

3. Fixing / Setting of Objective: In this step, researcher/ investigator requires to fix problem(s) and to set the objective(s) for study.

4. Setting up of Hypothesis if any: Here, the hypothesis to be tested is to be framed of. Normally, a null hypothesis is framed of against an alternative hypothesis with a level of significance (and also with power of the test if necessary).

5. Perform Experimentation (for Experimental Research)/ Search for Logic / Derivation Method (for Theoretical Research): In this step, experimentation is performed, or survey is conducted depending upon the requirement if the research is of experimental type. For theoretical research, logic for (or method of derivation of) development of theory is searched for in this step.

6. Collection of Information/Observation/Data: In this step, data/observation/information is collected for experimental research.

7. Scrutiny of Data: The jobs in this step consist of

i. Detection of Necessary Data \& Unnecessary Data etc.,

ii. Remove Unnecessary / Irrelevant Data,

iii. Verification of Error(s) in Data,

iv. Correct Error(s) from Data (having Error) if Possible,

v. Remove Data having Error(s) if Not Possible to Correct,

vi. Detect Qualified Observation /Data (for Analysis),

vii. Detect Unqualified Observation /Data (Not to be used in Analysis).

8. Classification of Data: Classification of data/observation/ information, representation of data/observation/information, Tabulation of data/observation/information, Conversion of form of data/observation/information from the form in collection to the required form is to be done in this step. 
9. Analysis of Data: Analysis of data/observation/ information is to be done in this step. The two broad aspects of analysis are determination (estimation in statistical terminology) and testing of hypothesis.

10. Interpretation of Results: Results/outcomes/findings obtained in the earlier stage, are interpreted in this stage.

11. Drawing of Conclusion: Based on the results/outcomes/ findings and interpretations obtained in the earlier two stages, conclusions/inferences are drawn in this stage.

\section{Concluding Remark}

The works to be done in bioscience research and the jobs to be done in statistics are similar. Thus, statistics is fully associated to bioscience research. Also, in any research in bioscience the items namely Scrutiny of Data; Classification of Data; Analysis of Data; Interpretation of Results/Findings \& Drawing of Conclusion / Inference, Prescription, Recommendation etc. cannot be performed without the help of statistical method(s). That is why statistics can be regarded as essential and unavoidable tool of bioscience research. The development of bioscience progresses with the development of statistics due to the need of its application in bioscience research and conversely the development of statistics progresses due to the need of new and new statistical methods in bioscience research.

The discipline of biostatistics, which is the application of statistics to a wide range of topics in bioscience has been developed due to the need of statistical methods especially for bioscience research. The concept, meaning, definition and significance of biostatistics are available in many literatures [25-29].

\section{References}

1. Maistrov LE (1974) Probability theory a historical sketch. Academic Press, New York, UK, p. 1-10.

2. Bayes $\mathrm{T}$ (1763) Thomas Bays essay towards solving a problem in the doctrine of chances. (Studies in the history of probability and statistics)", Reproduced from Philos. Trans Roy Soc, London Ser A53, with a biographical note by GA Barnerd, in Biometrika 45: 293-315.

3. Denzin NK, Lincoln Y (2005) The Sage Handbook of Qualitative Research, ( $3^{\text {rd }}$ edn), Sage Publications, USA.

4. Landwehr JM, Watkins AE (1995) Exploring Data, Palo Alto, Dale Seymour Publications, USA.

5. Rubenstein RN, Craine TV, Butts TR (1995) Teacher's Edition Integrated Mathematics. Houghton Mifflin Inc, Boston, USA.

6. Iverson MG, Gergen M (1997) Statistics: The conceptual approach. Springer- Verlag, New York, USA.

7. Chakrabarty D (2018) Understanding the space of research, Biostatistics and Biometrics Open Access Journal, 4(5): 1-17.
8. Savage LJ (1954) The foundations of statistics. John Wiley, New York.

9. Von Mises R (1930) Veroyatnost'i statistika, Moscow-Leningard, (English Edition: "Probability and Statistics", Academic Press, New York, 1964).

10. Von Mises R (1931) Wahrscheinlichkeits Rechnung, English Edition by Geiringer.

11. Von Mises R (1938-1939) Ueber Aufteilungsund BesetzungsWahrscheinlichkeiten, Revve de la Faculte des Sciences de l' Universite d' Istanbul, NS, 4: 145-163.

12. Geiringer H (1957) Probability, Statistics and Truth. Allen G and Unwin Ltd., London.

13. Geiringer H (1964) Mathematical Theory of Probability and Statistics. Academic Press, New York, USA.

14. Von Mises R (1939) Probability, Statistics and Truth. MacMillan, England.

15. Lappan G, Frey JT, Fizgerald WM, Friel SN, Phillips ED (1998) Teacher's guide connected mathematics: Samples and populations, Menlo Park, Dale Seymour Publications, USA.

16. Ernst M (1982) The growth of biological thoughts: Diversity, evolution and inheritance. Harvard University Press, USA, ISBN 978-0-674-364462

17. Magner Lois N (2002) A history of the life sciences, revised and expanded. CRC Press. ISBN 978-0-203-91100-6.

18. Richards Robert J (2002) The romantic conception of life: Science and philosophy in the age of Goethe. University of Chicago Press, USA, ISBN 978-0-226-71210-9.

19. Anthony S (2013) The epic history of biology. ISBN 9781489963277.

20. Diane C Blankenship (2010) Applied Research and Evaluation Methods in Recreation. ISBN-13: 9780736077194.

21. Donald McBurney H (2006) Research Methods, ( $5^{\text {th }}$ edn), Thomson Learning, ISBN: 81-315-0047-0.

22. Kothari CR (2006) Research Methodology Methods and Techniques, 2/e, Vishwa Prakashan.

23. Kaplan D (2004a) The Sage Handbook of Quantitative Methodology for Social Sciences. Sage Publications, USA.

24. Kaplan D (2004b) The Sage Handbook of Quantitative Methodology for Social Sciences, Sage Publications, USA.

25. Indrayan A (2012) Medical Biostatistics, CRC Press, ISBN 978-1-43988414-0.

26. Erika Check H (2012) Biostatistics: Revealing analysis. Nature 482(7384): 263-265

27. Emmert Streib F, Dehmer M (2010) Medical biostatistics for complex diseases. Wiley-Blackwell, USA, ISBN 3-527-32585-9.

28. Wayne Daniel W (2012) Biostatistics: A foundation for Analysis in the Health Sciences, $\left(10^{\text {th }}\right.$ edn $)$. Wiley Series in Probability and Statistics.

29. Wayne Daniel W (2014) Biostatistics: Basic Concepts and Methodology for the Health Sciences. Wiley Series in Probability and Statistics. 

(c) (i) Creative Commons Attribution 4.0

For possible submissions Click Here

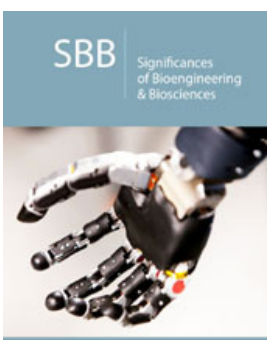

Significances of Bioengineering \& Biosciences

\section{Benefits of Publishing with us}

- High-level peer review and editorial services

- Freely accessible online immediately upon publication

- Authors retain the copyright to their work

- Licensing it under a Creative Commons license

- Visibility through different online platforms 
